Volume 43 | Number 2 | pp. 116-123 | (C) The Author(s) 2018. This is an Open Access article distributed under the terms of the Creative Commons Attribution licence (http://creativecommons.org/licences/by/4.0/), which permits unrestricted re-use, distribution, and reproduction in any medium, provided the original work is properly cited. I doi:10.1017/cha.2018.19

\title{
Variability in Developmental Outcomes of Foster Children: Implications for Research and Practice
}

\author{
Anouk Goemans, Mitch van Geel and Paul Vedder \\ Insitute of Education and Child Studies, Leiden University, Leiden, the Netherlands
}

\begin{abstract}
This article focuses on the variability in developmental outcomes of foster children and the implications for foster care research and practice. We first provide a brief overview of our previous work, where we have shown by means of meta-analysis and a longitudinal study that foster children greatly vary with respect to their developmental functioning. We then discuss that it is both the heterogeneity of developmental trajectories and the lack of an accurate model for predicting foster children's development that make the screening and monitoring of foster children's development important. We provide suggestions for screening and monitoring, and discuss the Brief Assessment Checklist as an example of a specific instrument available for screening and monitoring of vulnerable children exposed to severe social adversity. We conclude our article with directions to improve foster care and research on foster care, including a discussion of the effectiveness of and foster children's susceptibility to interventions, support for foster parents and the potential of large national and international studies.
\end{abstract}

Keywords: foster care, variability, developmental outcomes, screening and monitoring, implications for research and practice

\section{Introduction}

Children who are placed in foster families are a heterogeneous group and come from families with diverse characteristics and backgrounds. Foster children often come from families characterised by environments that pose a threat to children's development (e.g., low levels of social support, suboptimal parenting). In addition, many of these children have experienced childhood adversity such as abuse or neglect (Dubner \& Motta, 1999; Greeson et al., 2011; Oswald, Heil, \& Goldbeck, 2010; Turney \& Wildeman, 2017). Moreover, additional challenges may show up akin to the separation from children's biological parents (broken attachment) and the adjustment to a new family and living situation (Kinard, 1982). Previous studies have illustrated that many children in foster care have developmental problems upon entering foster care (Clausen, Landsverk, Ganger, Chadwick, \& Litrownik, 1998; James, 2004; Simms, Dubowitz, \& Szilagyi, 2000; Zorc et al., 2013), and although not many studies control for pre-placement adversities, foster children's backgrounds are likely to have an impact on foster children's development at the start of the placement in the foster family as well as later, during the foster placement (Scholte, 1997; Turney \& Wildeman, 2017; Wald, Carlsmith, \& Leiderman, 1988).
The aim of foster care is to offer a safe and stimulating home environment which helps foster children to recover from adversities. However, notwithstanding this aim, many foster children continue to experience developmental difficulties during the foster placement; they experience internalizing and externalizing problem behaviours (Maaskant, Van Rooij, \& Hermanns, 2014), adaptation problems (Berkoff, Leslie, \& Stahmer, 2006), and poor academic achievements (Berger, Cancian, Han, Noyes, \& RiosSalas, 2015; Jackson, 1994; O’Higgins, Sebba, \& Luke, 2015; Sebba et al., 2015).

Although many studies present a gloomy picture of the development of children in foster care, results have not been conclusive. Next to studies showing negative or no effects of foster care, some studies show that foster care improves children's functioning (Ahmad et al., 2005; Barber \& Delfabbro, 2005; Fernandez, 2009; Horwitz, Balestracci, \& Simms, 2001; White, 1997). This article focuses on the variability in developmental outcomes of foster children

ADDRESS FOR CORRESPONDENCE: Anouk Goemans, Institute of Education and Child Studies, Leiden University,

Wassenaarseweg 52, 2333 AK Leiden, the Netherlands.

E-mail: a.goemans@fsw.leidenuniv.nl 
and its implications for foster care research and practice. We start with a brief overview of our previous work (Goemans, 2017), where we have shown by means of meta-analysis and a longitudinal study that foster children greatly vary with respect to their developmental functioning. We then discuss that it is both the heterogeneity of developmental trajectories and the lack of an accurate model for predicting foster children's development that add to the importance of the screening and monitoring of foster children's development. We provide suggestions for screening and monitoring and conclude our article with directions to improve foster care and research on foster care.

\section{Variability in Foster Children's Development: Findings from our Previous Work}

Research areas characterized by a wide variety of sometimes conflicting findings make it difficult to gain an accurate overview of the domain. Research examining foster children's development is full of inconsistent or varied findings.

Meta-analysis is a statistical method to derive a systematic, quantitative overview of the empirical scientific literature (Borenstein, Hedges, Higgins, \& Rothstein, 2009; Cooper, Hedges, \& Valentine, 2009). Another important incremental value of meta-analysis is that a more reliable overall effect size is obtained than is available from the individual studies (Borenstein et al., 2009; Cooper et al., 2009). This is also relevant with respect to research on foster children's development, because achieving a correct overview here is even more difficult due to the many small studies, yielding unstable findings using non-randomised samples (Jackson, Gabrielli, Tunno, \& Hambrick, 2012).

In a series of meta-analyses we examined foster children's longitudinal developmental outcomes. A systematic literature search resulted in 29 studies $(n=2,904)$ and by means of meta-analysis we found that, once in foster care, children's functioning in terms of cognitive, adaptive and behavioural development on average, did not change (see Goemans, Van Geel, \& Vedder, 2015 for a more detailed description of the systematic literature search, inclusion and exclusion criteria, coding decisions, analyses and a more extensive discussion of the results). Moreover, we found that there was a large variation between the longitudinal studies included in the meta-analyses with respect to foster children's development. We performed several moderator analyses to examine whether differences in design (study length, sample size, attrition, type of publication) or sample (foster children's mean age) could explain this variation in outcomes. Most of the moderator analyses yielded nonsignificant findings and the information needed for other interesting moderator analyses (e.g, with regard to placement history, preplacement adverse childhood experiences) was not reported in the individual studies. It was therefore not possible to identify characteristics that were likely to be critical for improving foster children's development (Goemans et al., 2015).

The findings of the meta-analysis provided the context that lent scientific as well as social relevance to our longitudinal study. With this longitudinal study, we aimed to further our insight in a variety of foster child, foster family and foster placement characteristics related to the development of children in foster care. From October 2014 to October 2015, we performed a three wave longitudinal study wherein we asked Dutch foster parents to complete an online questionnaire. In a sample of 446 foster children between 3 and 17 years old, we found several characteristics related to foster children's development, such as positive parenting, foster children receiving interventions, foster parents thinking about quitting foster care, the presence of biological children of foster parents and the availability of plans for reunification (see Goemans, Van Geel, \& Vedder, 2016 for a more detailed description of the participants, instruments, procedure, analyses, and a more extensive discussion of the results). These characteristics partly explained foster children's development. Although we should be careful in conclusions about prevalence because of our non-randomized sample, another important finding of the longitudinal study is that foster children varied widely in psychosocial functioning: approximately $45 \%$ scored within the "normal" range on the Strengths and Difficulties Questionnaire (SDQ) (Goodman, 1997; Van Widenfelt, Goedhart, Treffers, \& Goodman, 2003), 15\% within the borderline range, and $40 \%$ in the clinical range. This means that there is a large group of foster children who demonstrate normative development, but also a sizeable group that has serious developmental problems. Therefore, our longitudinal study confirms the large variability in developmental outcomes of children in foster care.

\section{Importance of Screening and Monitoring}

It is both the heterogeneity of developmental trajectories and the lack of an accurate model for predicting the development of children in foster care that lends significance to screening and monitoring of foster children's development. At the moment, it cannot be guaranteed that children placed in foster care will develop well, nor can we accurately predict whether foster children will experience a positive development or not. Therefore, we advise foster care agencies to systematically implement screening and monitoring measures in order to track the development of foster children. This enables timely identification of those foster children who experience developmental difficulties and are at risk for negative developmental trajectories and breakdown (Newton, Litrownik, \& Landsverk, 2000; Oosterman et al., 2007).

We encourage the use of validated measures for screening and monitoring because their psychometric properties are well-studied and it is also known how these measures relate to relevant child outcomes and family characteristics. Three recent reviews give an overview of instruments available for 
screening and monitoring of vulnerable children exposed to severe social adversity, including maltreatment (Denton, Frogley, Jackson, John, \& Querstret, 2016; Lewis, 2014; Milne \& Collin-Vézina, 2015). Specialised instruments for this population are needed to capture the full range of developmental problems that are encountered by children in foster care, such as various attachment- and trauma-related difficulties. It turns out that there are only a few specialised measures that focus on psychosocial difficulties specifically manifested by children in foster care (Levitt, 2009). Among these instruments is the Brief Assessment Checklist (BAC) (Tarren-Sweeney, 2013) for which we studied the psychometric properties in a Dutch sample of foster children (Goemans, Tarren-Sweeney, Van Geel, \& Vedder, 2017). Our study showed that both the child and adolescent versions of the BAC measures perform both screening and monitoring functions well. Its screening accuracy, internal reliability and concurrent validity were good. Advantages of the BAC measures are that they pose very specific questions related to, for example, attachment behaviour, such as "craves affection" or "relates to strangers as if they were family".

Despite the aforementioned advantages of the BAC, future research is needed to assess the value of the BAC compared to other measures. It would be of interest to examine whether the BAC identifies a group of children that is not identified by measures such as the SDQ because trauma and attachment behaviours fall outside the "regular" diagnostic behaviours assessed with the latter instrument (Dölitzsch, Kölch, Fegert, Schmeck, \& Schmid, 2016; Iwaniec, 2006). This might mean that the BAC shows greater sensitivity than the SDQ with foster children. Good sensitivity is certainly required, but very high sensitivity is likely to come with a risk of incorrectly identifying children as having psychosocial difficulties while there are actually no problems (i.e., false positives). Considering the existing burden on the service capacity of the mental health system and support services, the consequences of high sensitivity in daily practice might have negative consequences for the true positives in terms of capacity and waiting time to start a more comprehensive assessment. It is for this reason that we argue for future research to more extensively study the screening properties of the BAC measures in order to validate a screening cut-point and to reduce false positives and false negatives. Optimal screening cut-points are related to the screening accuracy of a measure. A screening cut-point refers to a certain score at which foster children who receive a score at or above the cut-point are evaluated as likely to have psychosocial difficulties and are eligible for further assessment. Examining cut-points would inform what is the best trade-off between sensitivity and specificity (i.e., the quality of identifying true negatives).

In addition to examining cut-points and the relation of the BAC with other measures, researchers and foster care professionals should also establish collaborations in order to improve the validity as well as the feasibility of screening and monitoring of children in foster care. Working with an online system would be helpful in the organisation of systematic screening and monitoring. In the case of new foster placements, foster parents could be invited at the start of the placement and then again at regular intervals to complete standardised measures such as the BAC measures. Through the use of new technologies, screening and monitoring can be organised in such a way that standardized scoring is done instantaneously and the findings are made directly available to foster care professionals and automatically stored in the client's files. Such standardised, automated procedures could inform professionals' guidance and support for foster families and children. Although implementing systematic screening and monitoring requires an additional effort from all parties involved, we think that it will pay back in the short as well as in the long run. Insight into foster children's developmental trajectories will allow more timely targeted support services. It is important to invest time and effort in foster children and foster families who are most in need of it.

\section{Directions for Improvements in Foster Care}

Screening and monitoring resulting in the opportunity to provide timely support for foster children will not be a panacea for all developmental difficulties of foster children. There certainly are some promising interventions aimed at foster children or foster parents, such as Attachment and Biobehavioral Catch-up (ABC), Multidimensional Treatment Foster Care (MTFC), Incredible Years (IY), Keeping Foster Parents Trained and Supported (KEEP) (Leve et al., 2012; Roberts, Glynn, \& Waterman, 2016; Ruff, Aguilar, \& Clausen, 2016; Yarger, Hoye, \& Dozier, 2016). However, we warn against too much optimism about the effects of interventions for foster children and foster families. There are several overview studies indicating the limited effects of interventions aimed at foster children and foster parents (Benesh \& Cui, 2016; Dorsey et al., 2008; Macdonald et al., 2016; Rork \& McNeil, 2011; Turner, Macdonald, \& Dennis, 2007). It is therefore important to further develop and examine new interventions for foster care (Dorsey et al., 2008; Hambrick, Oppenheim-Weller, N'zi, \& Taussig, 2016).

However, while stimulating the development of new interventions there is reason to remain modest when it comes to interventions with foster children. It can be questioned whether foster children are susceptible to interventions that are aimed at promoting their development. In our longitudinal study, we did not find bidirectional relations between foster children's developmental functioning and foster parents' stress (Goemans, Van Geel, \& Vedder, 2017). In reaction to the absence of bidirectional relations, we discussed whether foster parents can, more generally, cause their foster children to benefit from the new home environments. Doubt about a positive answer is linked to the so-called "delimits of parental influence" for certain groups of children, such as adoptive or foster children 
(O'Connor, 2002). Secure attachment and internal attachment representations of foster children might play a role in this limited susceptibility to parental influences (McWey, 2004; Milan \& Pinderhughes, 2000). Adverse childhood experiences increase the risk of insecure attachment with biological caregivers (Bovenschen et al., 2016; Cyr, Euser, Bakermans-Kranenburg, \& Van IJzendoorn, 2010; McWey, 2004) and increase the chance of developing insecure attachment strategies. When transferred to new relationships with foster parents, such strategies can prove problematic and alienating (Oosterman, Schuengel, \& Dozier, 2012; Stovall-McClough, \& Dozier, 2004) and prevent foster children benefitting from the supportive, sensitive and responsive environment that foster families generally offer.

Given the fact that foster children's behaviour problems are fairly stable over time, and interventions only partly or just for a short time reduce foster children's behaviour problems, we need to find other ways to support foster children's developmental trajectories and to prevent the risk of placement breakdown. Support for foster parents might be a means toward this end, especially because we found in our longitudinal study that foster children's behaviour problems predict foster parents' stress (Goemans, Van Geel et al., 2017). Consistent with previous studies (Farmer, Lipscombe, \& Moyers, 2005; Hurlburt et al., 2010; Jones \& Morisette, 1999; McCarthy, Janeway, \& Geddes, 2003), our study showed that a considerable group of foster parents had above average levels of parental stress (Goemans, Van Geel et al., 2017). Although we found that foster parents' stress did not have an effect on foster children's internalising and externalising behaviour problems, we know from previous studies that parental stress can be negatively related to foster parents' motivation to continue fostering (Brown \& Bednar, 2006; Farmer et al., 2005) and that parental stress therefore poses a risk for foster placement breakdown (Van Rooij, Maaskant, Weijers, Weijers, \& Hermanns, 2015). Foster care professionals should be alert to foster parents' stress.

Although previous studies on foster parent stress have not been conclusive with their findings on what is most stressful for foster parents, communication and relationships with the foster care agency and professionals are mentioned as important sources of stress (Blackburn, 2016; Van den Bergh, 2013). Some promising initiatives focusing on stress reduction are worth mentioning. One example is a helpline for foster parents. Blackburn (2016) examined the effects of the "Fosterline" in England, which is a national independent helpline for foster parents, both current and prospective, to obtain confidential advice and support. It was shown that obtaining support by calling this helpline positively influenced foster parents' motivation and intentions to continue fostering. Another initiative to support foster parents is respite care (Madden et al., 2016), which refers to a short-term foster placement, such as part-time foster care, to provide relief for foster parents. Respite care has been shown to decrease the feelings of stress and burden in foster parents (Madden et al., 2016; Owens-Kane, 2007). Foster care professionals might want to consider raising awareness of this option of part-time foster care in a fulltime foster care arrangement, thereby increasing the access to formal respite care in order to reduce stress levels of foster parents and promote placement stability and foster children's wellbeing (Madden et al., 2016).

\section{Directions for Future Research}

The variability of foster children's development and the lack of an accurate model to predict foster children's development also provide important directions for future research. Future research should try to answer the question why some foster care trajectories are more successful in terms of children's development than others. However, conducting research on foster children can be challenging (Jackson et al., 2012; Maaskant, 2016). When setting up new studies on foster children, researchers should preferably learn and draw inspiration from past studies and carefully consider their research designs (NSCAW Research Group, 2002). Previous (longitudinal) studies on foster children often had small sample sizes making it difficult to test complex models and find robust effects. There are, however, some examples of large national studies on children (also foster children) in child welfare. Examples are studies such as the NSCAW, the representative longitudinal survey of American children and families who have been the subject of investigation by Child Protective Services, the Pathways of Care Longitudinal Study (POCLS), a large-scale prospective longitudinal study of children and young people in out-of-home care in Australia, and the Canadian Incidence Study (CIS), a national initiative to collect data on children who come to the attention of child welfare due to suspected abuse or neglect. Combining research efforts and strengths to perform a national study in the Netherlands, but also in other countries, would create many opportunities to generate a rich database that would allow for important advances in the development and validation of knowledge on foster care. Moreover, a cross-national study would allow for the comparison of child welfare policies between different countries and its effect on foster children's outcomes. As an example, differences between child welfare orientations and policies with respect to adoption from care vary greatly between countries and findings cannot easily be generalised beyond policy and country borders without probing the country or policy specific validity about the measures and their impact on foster children and families (Gilbert, 2012; Tarren-Sweeney, 2016).

We realise that building large national and international studies is a major and difficult step. In the meantime, Trocmé, Roy, and Esposito (2016) give some helpful suggestions for starting to build research capacity in child welfare settings that would be required for a large national study, but could also provide a starting point for collaboration be- 
tween foster care professionals and researchers on smaller studies. Trocmé et al. (2016) say there is little research on the efficacy of child welfare services in Canada. Child welfare agencies do not always have a strong research culture and their research capacity is sometimes limited. This may be resolved by collaboration between researchers and child welfare professionals in participatory research projects. Collaborations between researchers and practitioners would be an important step toward building research capacity (Trocmé et al., 2016). It would likely be experienced as an asset if the university's research infrastructure was placed at the service of community agencies. By doing so, firm research partnerships could be formed wherein researchers have access for research in child welfare settings and child welfare agencies can make better use of research findings which are adapted to and indicate significance in particular child welfare practices. Moreover, welfare professionals could be trained to become practitioner researchers (Trocme et al., 2016). Another suggestion in order to perform research is to make use of administrative child welfare data (Green et al., 2015; Huffhines et al., 2016; Kum, Stewart, Rose, \& Duncan, 2015; Lery, Haight, \& Alpert, 2016). Administrative records can provide supplementary information or an additional perspective on foster children's development. Although Green et al. (2015) point at the potential limitations of using administrative records, such as underreporting, privacy concerns and concerns with confidentiality and reliability of the information provided by the records, they stress that the benefits can outweigh the challenges. They provide an overview of the lessons learned and make several recommendations, such as ensuring adequate time and resources to establish agreements with child welfare agencies and how to deal with the variability in child welfare system processes in order to ensure comparability within and between agencies. In order to make the most of administrative records, child welfare agencies are encouraged to continue to improve their record keeping (Green et al., 2015).

\section{Conclusion}

This article highlights that foster children vary greatly with respect to their developmental functioning. Both our metaanalysis and longitudinal study showed large variability in the development of foster children. Given the large heterogeneity of foster children's developmental trajectories and the absence of accurate models that can predict how foster children will develop, we advise foster care agencies to systematically implement screening and monitoring measures in order to capture foster children's developmental diversity. This enables a timely identification of those foster children at risk for negative developmental trajectories and breakdown. In addition, we recommend developing national and international studies to increase our knowledge with respect to success factors in foster children's development.

\section{References}

Ahmad, A., Qahar, J., Siddiq, A., Majeed, A., Rasheed, J., Jabar, F., \& von Knorring, A. L. (2005). A 2-year follow-up of orphans' competence, socioemotional problems and posttraumatic stress symptoms in traditional foster care and orphanages in Iraqi Kurdistan. Child: Care, Health And Development, 31(2), 203-215.

Barber, J., \& Delfabbro, P. (2005). Children's adjustment to long-term foster care. Children and Youth Services Review, 27(3), 329-340.

Benesh, A. S., \& Cui, M. (2016). Foster parent training programmes for foster youth: A content review. Child \& Family Social Work, 22(1), 548-559, doi: 10.1111/cfs.12265.

Berger, L. M., Cancian, M., Han, E., Noyes, J., \& RiosSalas, V. (2015). Children's academic achievement and foster care. Pediatrics, 135(1), e109-e116, doi: 10.1542/peds. 2014-2448.

Berkoff, M. C., Leslie, L. K., \& Stahmer, A. C. (2006). Accuracy of caregiver identification of developmental delays among young children involved with child welfare. Journal of Developmental \& Behavioral Pediatrics, 27(4), 310-318.

Blackburn, C. (2016). The role of a national fostering helpline in the recruitment and retention of foster carers: Implications for policy and fostering practice. Adoption \& Fostering, 40(2), 167-178.

Borenstein, M., Hedges, L. V., Higgins, J. P., \& Rothstein, H. R. (2009). Introduction to meta-analysis. Hoboken: John Wiley \& Sons.

Bovenschen, I., Lang, K., Zimmermann, J., Förthner, J., Nowacki, K., Roland, I., \& Spangler, G. (2016). Foster children's attachment behavior and representation: Influence of children's pre-placement experiences and foster caregiver's sensitivity. Child Abuse \& Neglect, 51, 323-335.

Brown, J. D., \& Bednar, L. M. (2006). Foster parent perceptions of placement breakdown. Children and Youth Services Review, 28(12), 1497-1511.

Clausen, J. M., Landsverk, J., Ganger, W., Chadwick, D., \& Litrownik, A. (1998). Mental health problems of children in foster care. Journal of Child and Family Studies, 7(3), 283-296.

Cooper, H., Hedges, L. V., \& Valentine, J. C. (2009). The handbook of research synthesis and meta-analysis. New York: Russell Sage Foundation.

Cyr, C., Euser, E. M., Bakermans-Kranenburg, M. J., \& Van IJzendoorn, M. H. (2010). Attachment security and disorganization in maltreating and high-risk families: A series of meta-analyses. Development and Psychopathology, 22(01), 87-108.

Denton, R., Frogley, C., Jackson, S., John, M., \& Querstret, D. (2016). The assessment of developmental trauma in children and adolescents: A systematic review. Clinical Child Psychology and Psychiatry, 22(2), 260-287, doi: 10.1177/1359104516631607.

Dölitzsch, C., Kölch, M., Fegert, J. M., Schmeck, K., \& Schmid, M. (2016). Ability of the child behavior checklist-dysregulation profile and the youth self reportdysregulation profile to identify serious psychopathology 
and association with correlated problems in high-risk children and adolescents. Journal of Affective Disorders, 205, 327-334.

Dorsey, S., Farmer, E. M., Barth, R. P., Greene, K. M., Reid, J., \& Landsverk, J. (2008). Current status and evidence base of training for foster and treatment foster parents. Children and Youth Services Review, 30(12), 1403-1416.

Dubner, A. E., \& Motta, R. W. (1999). Sexually and physically abused foster care children and posttraumatic stress disorder. Journal of Consulting and Clinical Psychology, 67(3), 367-373.

Farmer, E., Lipscombe, J., \& Moyers, S. (2005). Foster carer strain and its impact on parenting and placement outcomes for adolescents. British Journal of Social Work, 35(2), 237253.

Fernandez, E. (2009). Children's wellbeing in care: Evidence from a longitudinal study of outcomes. Children and Youth Services Review, 31(10), 1092-1100.

Gilbert, N. (2012). A comparative study of child welfare systems: Abstract orientations and concrete results. Children and Youth Services Review, 34, 532-536.

Goemans, A. (2017). The development of children in foster care. Doctoral dissertation, Leiden: Leiden University.

Goemans, A., Van Geel, M., \& Vedder, P. (2015). Over three decades of longitudinal research on the development of foster children: A meta-analysis. Child Abuse \& Neglect, 42, 121-134.

Goemans, A., Van Geel, M., \& Vedder, P. (2016). Psychosocial functioning in Dutch foster children: The relationship with child, family, and placement characteristics. Child Abuse \& Neglect, 56, 30-43.

Goemans, A., Tarren-Sweeney, M., Van Geel, M., \& Vedder, P. (2017). Psychosocial screening and monitoring for children in foster care: Psychometric properties of the brief assessment checklist in a dutch population study. Clinical Child Psychology and Psychiatry, 23(1), 9-24, doi: 10.1177/1359104517706527.

Goemans, A., Van Geel, M., \& Vedder, P. (2017). Foster children's psychosocial development and foster parents' stress: Testing a transactional model. Journal of Child and Family Studies, 27(3), 990-1001.

Goodman, R. (1997). The strengths and difficulties questionnaire: A research note. Journal of Child Psychology and Psychiatry, 38(5), 581-586.

Green, B. L., Ayoub, C., Bartlett, J. D., Furrer, C., Von Ende, A., Chazan-Cohen, R., ... Nygren, P. (2015). It's not as simple as it sounds: Problems and solutions in accessing and using administrative child welfare data for evaluating the impact of early childhood interventions. Children and Youth Services Review, 57, 40-49.

Greeson, J. K., Briggs, E. C., Kisiel, C. L., Layne, C. M., Ake, G. S. III, Ko, S. J., ... Pynoos, R. S. (2011). Complex trauma and mental health in children and adolescents placed in foster care: Findings from the national child traumatic stress network. Child Welfare, 90(6), 91-108.

Hambrick, E. P., Oppenheim-Weller, S., N'zi, A. M., \& Taussig, H. N. (2016). Mental health interventions for children in foster care: A systematic review. Children and Youth Services Review, 70, 65-77.

Horwitz, S. M., Balestracci, K. M., \& Simms, M. D. (2001). Foster care placement improves children's functioning. Archives of Pediatrics \& Adolescent Medicine, 155(11), 12551260.

Huffhines, L., Tunno, A. M., Cho, B., Hambrick, E. P., Campos, I., Lichty, B., \& Jackson, Y. (2016). Case file coding of child maltreatment: Methods, challenges, and innovations in a longitudinal project of youth in foster care. Children and Youth Services Review, 67, 254-262.

Hurlburt, M. S., Chamberlain, P., DeGarmo, D., Zhang, J., \& Price, J. M. (2010). Advancing prediction of foster placement disruption using brief behavioral screening. Child Abuse \& Neglect, 34(12), 917-926.

Iwaniec, D. (2006). The emotionally abused and neglected child: Identification, assessment and intervention: A practice handbook. Chichester: John Wiley \& Sons.

Jackson, S. (1994). Educating children in residential and foster care. Oxford Review of Education, 20(3), 267-279.

Jackson, Y., Gabrielli, J., Tunno, A. M., \& Hambrick, E. P. (2012). Strategies for longitudinal research with youth in foster care: A demonstration of methods, barriers, and innovations. Children and Youth Services Review, 34(7), 12081213.

James, S. (2004). Why do foster care placements disrupt? An investigation of reasons for placement change in foster care. Social Service Review, 78(4), 601-627.

Jones, G., \& Morrissette, P. J. (1999). Foster parent stress. Canadian Journal of Counselling, 33(1), 13-27.

Kinard, E. M. (1982). Experiencing child abuse: Effects on emotional adjustment. American Journal of Orthopsychiatry, 52(1), 82-91.

Kum, H.-C., Stewart, C. J., Rose, R. A., \& Duncan, D. F. (2015). Using big data for evidence based governance in child welfare. Children and Youth Services Review, 58, 127-136.

Lery, B., Haight, J. M., \& Alpert, L. (2016). Four principles of big data practice for effective child welfare decision making. Journal of Public Child Welfare, 10(4), 466-474.

Leve, L. D., Harold, G. T., Chamberlain, P., Landsverk, J. A., Fisher, P. A., \& Vostanis, P. (2012). Practitioner review: Children in foster care-vulnerabilities and evidence-based interventions that promote resilience processes. Journal of Child Psychology and Psychiatry, 53(12), 1197-1211.

Levitt, J. M. (2009). Identification of mental health service need among youth in child welfare. Child Welfare, $88(1)$, 27-48.

Lewis, S. E. (2014). Assessment of mental health for looked after children. Doctoral dissertation, Hull, United Kingdom: University of Hull.

Maaskant, A. (2016). Placement breakdown in foster care: Reducing risks by a foster parent training program?. Doctoral dissertation, Amsterdam, the Netherlands: University of Amsterdam.

Maaskant, A. M., Van Rooij, F. B., \& Hermanns, J. M. (2014). Mental health and associated risk factors of Dutch school aged foster children placed in long-term foster care. Children and Youth Services Review, 44, 207-216. 
Macdonald, G., Livingstone, N., Hanratty, J., McCartan, C., Cotmore, R., Cary, M., et al. (2016). The effectiveness, acceptability and cost-effectiveness of psychosocial interventions for maltreated children and adolescents: An evidence synthesis. Health Technology Assessment, 20(69), doi: 10.3310/hta20690.

Madden, E. E., Chanmugam, A., McRoy, R. G., Kaufman, L., Ayers-Lopez, S., Boo, M., \& Ledesma, K. J. (2016). The impact of formal and informal respite care on foster, adoptive, and kinship parents caring for children involved in the child welfare system. Child and Adolescent Social Work Journal, 33(6), 523-534.

McCarthy, G., Janeway, J., \& Geddes, A. (2003). The impact of emotional and behavioural problems on the lives of children growing up in the care system. Adoption \& Fostering, 27(3), 14-19.

McWey, L. M. (2004). Predictors of attachment styles of children in foster care: An attachment theory model for working with families. Journal of Marital and Family Therapy, 30(4), 439-452.

Milan, S. E., \& Pinderhughes, E. E. (2000). Factors influencing maltreated children's early adjustment in foster care. Development and Psychopathology, 12(1), 63-81.

Milne, L., \& Collin-Vézina, D. (2015). Assessment of children and youth in child protective services out-of-home care: An overview of trauma measures. Psychology of Violence, 5(2), 122-132.

Newton, R. R., Litrownik, A. J., \& Landsverk, J. A. (2000). Children and youth in foster care: Disentangling the relationship between problem behaviors and number of placements. Child Abuse \& Neglect, 24(10), 1363-1374.

NSCAW Research Group. (2002). Methodological lessons from the national survey of child and adolescent well-being: The first three years of the USA's first national probability study of children and families investigated for abuse and neglect. Children and Youth Services Review, 24(6-7), 513-541.

O'Connor, T. G. (2002). Annotation: The effects' of parenting reconsidered: Findings, challenges, and applications. Journal of Child Psychology and Psychiatry, 43(5), 555-572.

O'Higgins, A., Sebba, J., \& Luke, N. (2015). What is the relationship between being in care and the educational outcomes of children?: An international systematic review. Oxford: Rees Centre for Research in Fostering and Education, University of Oxford.

Oosterman, M., Schuengel, C., \& Dozier, M. (2012). Inspelen op de drie basisbehoeften van jonge kinderen in pleeggezin [Responding to the three basic needs of young children in foster families]. In J. Vanderfaeillie, F. Van Holen, \& F. Vanschoonlandt (Eds.), Op weg met pleegzorg. Kansen risico's. [On track with foster care. Opportunities and risks] (pp. 296-307). Leuven: Acco.

Oosterman, M., Schuengel, C., Slot, N. W., Bullens, R. A., \& Doreleijers, T. A. (2007). Disruptions in foster care: A review and meta-analysis. Children and Youth Services Review, 29(1), 53-76.

Oswald, S. H., Heil, K., \& Goldbeck, L. (2010). History of maltreatment and mental health problems in foster children:
A review of the literature. Journal of Pediatric Psychology, 35(5), 462-472.

Owens-Kane, S. (2007). Respite care: Outcomes for kinship and non-kinship caregivers. Journal of Health \& Social Policy, 22(3-4), 85-99.

Roberts, R., Glynn, G., \& Waterman, C. (2016). 'We know it works but does it last?' The implementation of the KEEP foster and kinship carer training programme in England. Adoption \& Fostering, 40(3), 247-263.

Rork, K. E., \& McNeil, C. B. (2011). Evaluation of foster parent training programs: A critical review. Child \& Family Behavior Therapy, 33(2), 139-170.

Ruff, S. C., Aguilar, R. M., \& Clausen, J. M. (2016). An exploratory study of mental health interventions with infants and young children in foster care. Journal of Family Social Work, 19(3), 184-198.

Scholte, E. M. (1997). Exploration of criteria for residential and foster care. Journal of Child Psychology and Psychiatry, 38(6), 657-666.

Sebba, J., Berridge, D., Luke, N., Fletcher, J., Bell, K., Strand, S., ... O'Higgins, A. (2015). The educational progress of looked after children in England: Linking care and educational data: Oxford and Bristol: Rees Centre and University of Bristol. Retreived from http://reescentre.education.ox. ac.uk/wordpress/wp-content/uploads/2015/11/

EducationalProgressLookedAfterChildrenOverview Report_Nov2015.pdf

Simms, M. D., Dubowitz, H., \& Szilagyi, M. A. (2000). Health care needs of children in the foster care system. Pediatrics, 106, 909-918.

Stovall-McClough, K. C., \& Dozier, M. (2004). Forming attachments in foster care: Infant attachment behaviors during the first 2 months of placement. Development and Psychopathology, 16(02), 253-271.

Tarren-Sweeney, M. (2013). The brief assessment checklists (BAC-C, BAC-A): Mental health screening measures for school-aged children and adolescents in foster, kinship, residential and adoptive care. Children and Youth Services Review, 35(5), 771-779.

Tarren-Sweeney, M. (2016). The developmental case for adopting children from care. Clinical Child Psychology and Psychiatry, 21, 497-505.

Trocmé, N., Roy, C., \& Esposito, T. (2016). Building research capacity in child welfare in Canada. Child and Adolescent Psychiatry and Mental Health, 10(1), https://www.ncbi.nlm.nih.gov/pmc/articles/PMC4907254/ pdf/13034_2016_Article_103.pdf.

Turner, W., Macdonald, G., \& Dennis, J. A. (2007). Behavioural and cognitive behavioural training interventions for assisting foster carers in the management of difficult behaviour. Campbell Systematic Reviews, 3, $1-77$.

Turney, K., \& Wildeman, C. (2017). Adverse childhood experiences among children placed in and adopted from foster care: Evidence from a nationally representative survey. Child Abuse \& Neglect, 64, 117-129.

Van den Bergh, P. (2013). Pleegouders. Een investering waard. Een onderzoek naar redenen voor beëindiging van 
pleegouderschap. Leiden: Universiteit Leiden, Afdeling Orthopedagogiek.

Van Rooij, F., Maaskant, A., Weijers, I., Weijers, D., \& Hermanns, J. (2015). Planned and unplanned terminations of foster care placements in the Netherlands: Relationships with characteristics of foster children and foster placements. Children and Youth Services Review, 53, 130136.

Van Widenfelt, B. M., Goedhart, A. W., Treffers, P. D., \& Goodman, R. (2003). Dutch version of the strengths and difficulties questionnaire (SDQ). European Child \& Adolescent Psychiatry, 12(6), 281-289.

Wald, M. S., Carlsmith, J. M., \& Leiderman, P. H. (1988). Protecting abused and neglected children. Stanford: Stanford University Press.
White, D.S. (1997). Using social problem-solving interventions with foster children: A means of preventing later psychopathology. ( Doctoral dissertation). Fresno: California School of Professional Psychology.

Yarger, H. A., Hoye, J. R., \& Dozier, M. (2016). Trajectories of change in attachment and biobehavioral catch-up among high-risk mothers: A randomized clinical trial. Infant Mental Health Journal, 37(5), 525536.

Zorc, C. S., O’Reilly, A. L., Matone, M., Long, J., Watts, C. L., \& Rubin, D. (2013). The relationship of placement experience to school absenteeism and changing schools in young, school-aged children in foster care. Children and Youth Services Review, 35(5), 826-833. 